\title{
Link between HR practices and organizational performance in small firms: A case for manufacturing sector of Pakistan
}

\author{
Muhammad Fayyaz Sheikh, Syed Amjad Fareed Hasnu and Imran Khan*
}

COMSATS Institute of Information Technology, Abbottabad,Pakistan

\begin{tabular}{l}
\hline C H R O N I C L E \\
\hline Article history: \\
Received June5, 2015 \\
Received in revised format \\
August162015 \\
Accepted November82015 \\
Available online \\
November182015 \\
\hline Keywords: \\
HRM \\
HR Practices \\
HR Outcomes \\
Performance \\
RBV \\
\hline
\end{tabular}

\section{A B S T R A C T}

\begin{abstract}
Human Resource Management is relatively a new concept in small firms in Pakistan. The purpose of this study is to examine the impact of some of the human resource practices on organizational performance in small manufacturing firms. Using various statistical techniques confirming the adequacy of the model for small manufacturing firms, the result of the study based on the data collected through questionnaires, revealed that HR practices like recruitment, training, compensation and promotion do affect performance of organization. The intensity of these effect are positively mediated by HR outcomes i.e. employees skill, attitude and behavior. Thus it can be safely concluded that although the nature of HR practices in small firms is informal but the organizational performance can be improved by adopting carefully tailored HR practices keeping in mind the limited resources of small firms.
\end{abstract}

\section{Introduction}

Between mid-century and the late 1970s, Human Resource Management (HRM) research primarily focused on the development of valid and fair Human Resource (HR) practices in large organizations. These studies examine the relationship between various HR practices and individual performance and also highlight different forms of discrimination in Staffing and promotion. The latest research examines the implications of enhanced HR practices on organization-wide performance measures (Jakimow, 2011; Guest, 1997). This line of research has led some researchers to propose a normative model of HR practices, referred to as the "best practices" or "high commitment" theory of HRM. This model suggests that universally, certain HR practices, either separately or in combination are associated with improved organizational performance (MacDuffie, 1995). According to the high-commitment model, for instance, well-paid, well-motivated workers, in an atmosphere of mutuality and trust, generate higher productivity gains and lower unit costs (Klaas et al., 2012; Pfeffer, 1995). The validation of HRM practices with respect to individual and organization performance reinforces their importance as an area of study.

\footnotetext{
* Corresponding author. Tel: +92 3145185575

E-mail address:imrankjadoon@ciit.net.pk (I.Khan) 
Prior studies showed that small business owner/managers usually face HR related management problems. Recruiting, motivating and retaining employees seem to be a major challenge for small firms (Golhar\& Deshpande, 1997). Study of McEvoy (1984) discovered that effective management of human resources to be a good predictor of small firms' survival. Hornsby and Kuratko (2003) found that research in HRM still remains a large company phenomenon. Relatively little is understood regarding the HR related needs and practices of small firms (Cunningham, 2010). Particularly, the impact of HR practices on small business performance has rarely been studied. This research field seems to be terra incognita. Since numerous studies on the relationship between HRM and firm performance within large firms show evidence of a positive impact (MacDuffie, 1995), an increasing number of researchers stress the dire need for similar research in small business firms (Heneman et al., 2000). The purpose of the current study is an initiative to address this gap by developing and testing a conceptual framework linking HRM to organizational performance that fits small businesses. The main question in this study is whether the development of an intensive management of human resource is profitable for small organizations.

The study of HRM-performance relationship in small firms can contribute to understanding issues faced by the startup firms. These include human resource acquisition and deployment in start up and highly innovative ventures, the contribution of HRM practices to the survival of new ventures, and the role of resource acquisition, allocation and development, including human resources on the speed and direction of growth in high growth firms (Heneman et al., 2000). However, the most commonly explored HR practices in small business firms reflect operational needs and pragmatic concerns: record keeping, staffing, and motivation and retention activities (Hornsby \&Kuratko, 2003).

While some studies related to HRM in small firms have been conducted in different regions of Pakistan, there is no study on Hazara division. Hazara is the region of Khyber Pakhtunkhwa and includes six districts; Abbottabad, Battagram, Haripur, Kohistan, Mansehra and Tor Ghar. According to 2005 estimates, population of Hazara division, excluding Tor Ghar, was 4.5 million and its total area is $18013 \mathrm{~km}^{2}$.

\subsection{Objectives of Study}

Keeping in view, the importance of growing small firms and their share in the economic uplift of the people the objective of this study are;

- To test whether there exist formal or informal HRM practices and policies in small firms.

- To find out the impact of HR practices on the performance of small firms.

- To explore the most vital functional area of HRM for survival of the small firms in managers' views.

- To explore the functional area of HRM that plays a pivotal role in the growth of small firms.

Research on HRM practices and policies in small and medium sized business firms has gained increased attention in recent years. It is often assumed that there is a considerable homogeneity within smaller firms. However, a growing base of research evidence exhibits that there are many deviations to this assumption. Besides firm size other relevant contextual factors may influence HR practices too. The research is derived and tested on a model that predicts human resource management (HRM) practices of small firms based on their organizational context. Organization contextual variables include company size, strategy, technology, culture and the environment (especially other organizations or institutions). These variables have also been identified as possible predictors of HRM practices in several other studies (Kim \& Gao, 2010; Michael and Chris, 1990). 


\section{Defining Small Firm}

A small business is one that is privately owned and operated, with a small number of employees and relatively low volume of sales. The legal definition of "small" varies by country and by industry, ranging from fewer than 15 employees under the Australian Fair Work Act 2009, 50 employees in the European Union, and fewer than 500 employees to qualify for many U.S. Small Business Administration programs. According to the State Bank of Pakistan and SMEDA, a firm will be referred to be a small firm if it has up to 50 employees. In addition to number of employees, other methods used to classify small companies include annual sales (turnover), value of assets and net profit (balance sheet), alone or in a mixed definition. These criteria are followed by the European Union, for instance (headcount, turnover and balance sheet totals). Small businesses are usually not dominant in their field of operation.

Small businesses are common in many countries, depending on the economic system in operation. Typical examples include: convenience stores, other small shops such as bakery, hairdressers, tradesmen, lawyers, accountants, and restaurants, guest house, photographers, small-scale manufacturing, and online business, such as web design and programming, etc.

\subsection{Resource-Based View}

The resource-based view was popularized by Prahalad and Hamel in their book "Competing for the Future" (2001). Essentially, the view conceptualizes the firm as a bundle of resources. It is these resources, and the way that they are combined, that make firms different from one another and in turn allow a firm to deliver products and services in the market.

"Firms profess that people are the source of their competitive advantage, whether they be technological experts, accommodating customer service experts, or visionary managers. . .At a time of unparalleled technological development, it is the human resources that paradoxically spell success or failure for all firms, and especially entrepreneurial ones". The resource based view of the firm suggests that human resources can be a source of competitive advantage.

Many management scholars support the idea that a firm's ability to develop distinct and unique "bundles" of inter-linked HR practices associated with overall business strategy is a foundation of sustainable competitive advantage. Baron (2003, p. 253) had argued that the field of human resource management could benefit from looking more closely at HR processes within new and small firms. He suggested that new ventures started by entrepreneurs offer a "unique and potentially valuable business context for testing the principles and theories of HRM." Human capital in new ventures has been recognized as critical to venture success for some time (Deshpande \& Golhar, 1994), but it is only recently that scholars have meaningfully explored this aspect of new venture creation. In order to successfully add to the literature on HRM in entrepreneurial ventures, it is essential to know what work has already been done, and what we still do not understand well about new venture HRM. This research reviews what we know about HRM in entrepreneurial organizations in order to highlight important gaps in this understanding.

In an effort to explain HRM patterns in small firms, some scholars argue that an informal approach is more suited to the small firm. Hill and Stewart (2000) observed that smaller firms ought to be more flexible and informal to be able to cope with the elevated levels of environmental uncertainty. By comparison, others scholars assert that it is lack of foresight and/or resources that guides to less use of formal HR practices in small business firms. In addition to being characterized as informal, small firms are often held to be less specialized than larger firms (Jakimow, 2011). As the experience of the owner/manager shows that employees in smaller firms often have to perform a variety of tasks than their counterpart in bigger firms. Heneman et al., (2000) validate this trend within the small and medium 
sized business firms. In a random sample of 117 companies with less than 100 employees, they found that only 15 have a HRM department. Nevertheless, in that same study, the use of a HRM manager is associated with significantly higher retention rates.

\subsection{Human Resource Management (HRM)}

HRM has been defined as the process of attracting, developing, and maintaining a talented and energetic workforce to support organizational mission, objectives, and strategies. Audretsch and Thurik (2001) declare that effective HR practices are continuingly gaining importance in the new "knowledge-based" economy, as companies face the dual challenge of the need for more highly skilled employees together with a shortage of qualified labor. These challenges, joined with the third trend toward smaller firms in general, strengthen the need for effective HR practices in the small business firms.

\subsection{HRM Practices}

The nature of HR practices in small firms is different from larger firms. Researchers have described recruitment sources used by small firms as largely informal, usually by word of mouth from family, friends, or trusted employees (Marchington et al., 2003). Others report evidence of recruitment from newspaper advertisements, government employment agencies, employee referrals, and unsolicited applicants but do not relate these to firm size (Marchington et al., 2003). Selection procedures in small firms are noted to be largely based on the personal judgement of the owner-manager, established through one-to-one interviews (Golhar\& Deshpande, 1997) with emphasis on "fitting in" and little attention to paper qualifications or previous work record (Marchington et al., 2003). Consequently, good potential employees are not selected because they pose a threat to the valued independence of the owner-manager (Kim \& Gao, 2010). Similarly, training in small firms has been defined as informal and on-the-job, with little or no provision for management development Narrative descriptions of employee performance, assessment of their ability to meet targets and the use of rating scales, are appraisal methods frequently identified with small firms (Hornsby \& Kuratko, 2003), however, their association with specific firm sizes within the broad definition of small firm is not clear.

The development of practices associated with the management of middle managers over time is not clearly understood in the current literature (Klaas et al., 2012; Heneman et al., 2000). In light of these observations this study examines how HRM practices affect organizational performance, in particular, which practices are likely to become dominant and formal early in small firms and the implications for survival and competitiveness of small growing firms. Although there are countless combinations of HRM practices that result in identical organizational outcomes and although identifying exactly which HRM policies are associated with superior firm performance has been disappointing (Katou \& Budhwar, 2010), normally, the items used to constitute the HRM practices construct refer to the usual four key areas of resourcing, development, reward, and relations, in which human resources strategies may be developed (Cunningham, 2011).

\subsection{Performance}

The performance is a global concept that represents the results of human activities. Organizational performance is "the way in which an organization tries to be effective" (Griffin, 1991). An organization's performance can be measured in many different ways. The most common ways are in terms of efficiency or effectiveness. Performance is the attainment of organizational goals by using resources in an efficient and effective manner. Effectiveness and efficiency are viewed as sub components of performance. As Peter Drucker has stated, efficiency means "doing things right", and effectiveness means "doing the right things". The more complete definitions are that: "organizational efficiency refers to the amount of resources used to achieve an organizational goal", and organizational effectiveness is the degree to which organization achieves a stated objective. The more resources wasted during the production process, the more inefficient the manager is. If 
organizations are using their resources to attain their stated goals, the managers are effective. Finally, "productivity is the level of output of goods and services achieved by the resources of an organization" (Griffin, 1991). Effectiveness, efficiency, performance, and productivity are all important concepts for managers and organizations.

Several ways to categorize performance have been presented in the literature. One way is to distinguish the outcomes of organizational activities and the means by which these outcomes are reached. The former is often called "performance" while the latter is commonly referred to as "effectiveness" (Ukko, 2009). Interestingly enough, this distinction appeared only after 1978. Before that time both definitions were used interchangeably. Another way to characterize performance is to distinguish between financial and non-financial performance. The financial performance is often measured using traditional accounting KPIs such as ROA, ROS, EBIT, EVA ${ }^{\circledR}$ or Sales growth (Ittner \& Larcker, 1997). The advantage of these measurements is their general availability, since every profit oriented organization produces these figures for the yearly financial reporting (Chenhall \& Langfield-Smith, 2007). However, balance sheet manipulations and choices of accounting methods may also lead to values that allow only limited comparability of the financial strength of companies. The non-financial performance can be measured using operational KPIs. Market share, innovation rate or customer satisfaction are prominent examples. (Tangen, (2003) provides an overview of frequently used performance measures. Many researchers also use self reported measures to operationalize performance (Evans, 2004; Ittner \& Larcker, 1997). Chenhall and Langfield-Smith (1997) writes that there are various ways non-financial performance can be measured; however the performance can be hardly assessed without the link to corporate strategy. Despite the fact that performance measurement has received considerable attention, and that remarkable progress has been made over recent years, many manufacturing companies are still primarily relying on traditional cost-related performance measures, such as return on investment, profit margin and cash flow. This may seem as an irrational behavior, since the limitations of financial measures have been clearly documented. However, a major reason that underlies the lack of acceptance of newer performance measurement techniques is simply that neither industry nor academia has agreed on what new performance measures should be used or what criteria the selection of performance measures should be based on. The question of what particular performance measures to use is a complex task, and is not being made any easier as the number and types of performance measures available continue to grow.

\section{Methodology}

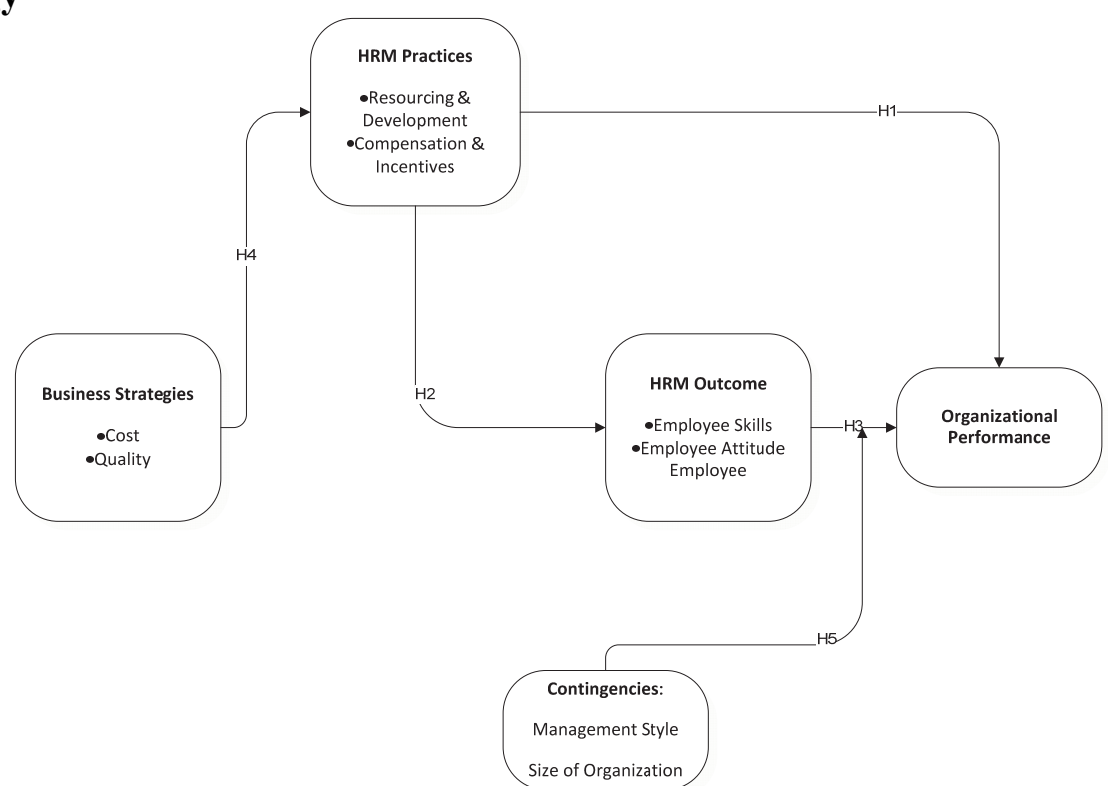

Fig. 1.Conceptual Framework (Based on Katou \& Budhwar, 2010) 


\section{Research hypotheses}

After a thorough study of the literature relating to problem statement, five basic hypotheses were established that include the following

$\mathrm{H}_{1}$ : There is strong relationship between HR practices and organizational performance in small firms.

$\mathrm{H}_{2}$ : HR practices positively mediate HR outcomes in small firms.

$\mathrm{H}_{3}$ : Positive relationship exists between HR outcomes and organizational performance.

$\mathrm{H}_{4}$ : Positive relationships of different strength exist between business strategies and HR practices.

$\mathrm{H}_{5}$ : Organizational context factor (Management style) and controls (like size and age) moderate the HRM-performance relationship.

\section{Sampling and data collection}

The Population of this study is the small manufacturing firms working in Hazara division. These firms include small industrial estates of Abbottabad, Mansehra, Heripur, and Hattar Industrial Estate along with other established units in the three aforementioned districts of Hazara. The sample for this study was taken from the small manufacturing firms of Abbottabad, Mansehra, and Haripur districts of Hazara division. The firms included in the sample ranged from marble and furniture to bakery and oil manufacturing firms. Moreover, only firms with a workforce between twenty and fifty are considered in conjunction with the guidelines of the State Bank of Pakistan.

The data was collected through structured questionnaires and interviews of the owner/managers.. The questionnaire was primarily constructed in line with the previous studies found during the literature review and it was originally designed in English and was translated into Urdu as majority of the owner/manager are comfortable with Urdu. The questionnaire is divided into four parts. The first part is designed to obtain the information about the status of Human resource in the organization as well as about the human resource practices in the respondent organization. The next section is intended to identify the Human resource outcomes, that is, about employees' skills, attitude, and behavior. The third section examined the nature of perceived performance of the organization. There are three multiple questions to answer. The last section examines the relevant organizational details as well as some information about the manager, the respondent. There are 42 questions in all. Some of the questions have multiple questions. In most of the questions five point likert scale was used in which the respondents were required to select one out of the five choices given to them, where 1 indicates Highly ineffective and 5 Highly effective. Before filling out the questionnaire the respondents were told about the aim of the research i.e. about the purpose of collecting the data from them. It was mentioned in the questionnaire that the information obtained from the questionnaire would be used for the intended purpose of academic research only and will not be provided to any other agency. The questionnaires were personally distributed among the respondent organizations and in some cases filled on the spot keeping in mind the schedule of the manager. According to the sources in Sarhad Development Authority (SDA), there are more than 550 small and medium manufacturing units spread over the three districts of Hazara region (personal interview). A total of 400 questionnaires were distributed among small manufacturing firms in districts Abbottabad, Mansehra, and Haripur. The majority of questionnaires were sent to the firms situated in Hattar Industrial Estate, Haripur, as it is supposed to have the maximum number of active firms. Very few active firms are available in district Abbottabad and Mansehra. After completion of questionnaires, it was found and analyzed that 280 questionnaires were filled properly. The rest of the respondents either have not returned or filled incomplete or not properly filled. Hence the final sample size was 280 respondents. 


\section{Results}

\subsection{Cronbach alpha}

The standardized set of questionnaire on 5 point-likert scale is used to measure all the variables in the structural (main) model. Construct's internal consistency was checked computing Cronbach (1951) alphas. The reliability of all the variables range from .531 to .762 except compensation and promotion which is .411. All other values of alpha other than recruitment and selection lies in the acceptable range as Hair et al. (1998) suggested that the minimum level of alpha must be above the minimum level of 0.60 and the value of alpha more than 0.5 , shows that the scale used can be considered reliable. The average variance extracted is within the acceptable range. The minimum requirement of average variance is .50 (Fornell \& Larcker, 1981). The figures in the following table indicate that the survey instrument for checking the model presented. Construct validity was examined by evaluating the percent of the total variance explained per dimension obtained by applying confirmatory factor analysis (CFA) using Amos (Katou \& Budwar, 2010).

One item of organizational performance showed that if it is deleted then alpha value will increase so that item is deleted because it is affecting reliability. The second item in resourcing and development variable showed increase in alpha value if it is deleted so that item is also eliminated. The alpha value of compensation and promotion is below the acceptable value, and despite removing different items its value does not improve so this variable is not considered for further analysis.

\section{Table 1}

Reliability Analysis of Items

\begin{tabular}{llll}
\hline Variable & Alpha Value & Sub variable & Alpha if item deleted \\
\hline Resourcing \& Development & 0.653 & Recruitment & 0.512 \\
& & Selection & 0.401 \\
& & Training & 0.728 \\
Compensation \&Incentives & \multirow{2}{*}{0.671} & Performance app. & 0.611 \\
& & Compensation & 0.633 \\
Involvement \&Job Design & 0.471 & promotion & 0.530 \\
& \multirow{2}{*}{0.623} & Participation & 0.321 \\
Employees Skills & Health and safety & 0.539 \\
& \multirow{2}{*}{0.681} & Cooperation with Management & 0.513 \\
Employees Attitude & Cooperation with employees & 0.632 \\
& \multirow{2}{*}{0.712} & Motivation & 0.531 \\
Employees Behavior & Satisfaction & 0.538 \\
Organizational Performance & \multirow{2}{*}{0.703} & Retention & 0.430 \\
& & Presence & 0.510 \\
Business Strategies & Effectiveness & 0.501 \\
& \multirow{2}{*}{0.620} & Efficiency & 0.670 \\
Contextual Factors & Satisfaction & 0.722 \\
& \multirow{2}{*}{0.669} & Cost & 0.637 \\
& & Quality & 0.521 \\
\hline
\end{tabular}

\subsection{Average Variance Extracted}

Raykov (2001) has demonstrated that Cronbach's alpha can be both an under- or over-estimate of reliability, contingent upon the amount of residual covariance amongst the cogeneric indicators. Thus, the more unmodelled residual covariance, the more Cronbach's alpha will be an overestimate of reliability. We must reverse the scoring of that reversed item before assessing reliability with alpha. In SEM terms, the reliability of an indicator is defined as the variance in that indicator which is not accounted for by measurement error. It is commonly represented by the squared multiple correlation 
coefficient, which ranges from 0 to 1 . However, because these coefficients are standardized, they are not useful for comparing reliability across subpopulations.

To test the reliability of the constructs, reviewers suggested to report composite reliability (CR) and Average Variance extracted (AVE) instead of Cronbach-alpha (internal consistency of measures). Composite reliability is like the reliability of a summated scale and average variance extracted is the variance in the indicators explained by the common factor, average trait-related variance extracted. AVE's above 0.5 are treated as indications of convergent validity. This use of CR and AVE emanates from the two-step procedure recommended. AVE varies from 0 to 1 , and it represents the ratio of the total variance that is due to the latent variable. A variance extracted of greater than 0.50 indicates that the validity of the entire construct and the individual variables is high. The composite reliability estimates the extent to which a set of latent construct indicators share in their measurement of a construct, whilst the average variance extracted is the amount of common variance among latent construct indicators (Hair et al., 1998).

The Average Variances Extract (AVE) of all the variables are good as they are falling in acceptable range. The minimum requirement of average variance is .50 (Fornell and Larcker, 1981). The average variances of the variable of human resource practices like recruitment and selection is equal to .66, training and performance appraisal is equal to .71, compensation and promotion .65. Similarly average variance for variables of human resource outcomes are for cooperation with management and employees is equal to .59 , for motivation and commitment is 0.63 and for retention and presence is 0.66.average variance for organizational performance is 0.59 . All the values are above .5 so the variables are reliable. The data is represented in the following table.

Table 2

Average Variance Extracted

\begin{tabular}{lll}
\hline Item\# & $\begin{array}{l}\text { Variable/Sub variables } \\
\text { HR Practices }\end{array}$ & Average varianceExtract \\
\hline 1 & Resourcing \& Development & 0.73 \\
2 & Compensation \& Incentives & 0.78 \\
3 & Involvement \& Job design & 0.65 \\
\hline \multicolumn{2}{l}{} \\
\hline 5 & HRM Outcomes & 0.73 \\
6 & Employee skills & 0.63 \\
7 & Employee Attitude & 0.69 \\
8 & Employee Behavior & 0.59 \\
9 & Organizational Performance & 0.77 \\
\hline
\end{tabular}

The bivariate correlations indicate the basic relationships given in the hypotheses (Katou \& Budwar, 2010). It was analyzed that each main/ basic variable have positive relationship with the other variables. The observed correlation of $r=0.645,0.379,0.474,0.326 \& .613(p=0.05)$ shows support for those relationships. It should be remembered here that this correlation is based on the data which is taken from concurrent managers-cum-owners.

The HR practices are less significantly related to organizational performance $(r=0.379$ at $p=0.05)$. Similarly, HR practices and HR outcomes are strongly and significantly related to each other $(\mathrm{r}=0.613$ at $p=0.05)$. Again the relationship between HR outcomes and organizational performance found strong and positive $(\mathrm{r}=0.645, \mathrm{p}=0.05)$

These result shows HR practices have an impact on organizational performance in part through their impact on employees' commitment, employees skills and employees behavior. The value of correlation coefficient (r), which is less than 0.3 , signifies a weak relationship. While, a value of $0.3-0.5$ show 
moderate relationship and a value greater than 0.5 up to 1 is supposed to be strong and perfect relationship.

\section{Measurement Model}

In the model the effect of exogenous variable HR Practices is measured on other endogenous variables (HR outcomes and Organizational Performance). In figure 1 the measurement model with exogenous variable $\mathrm{HR}$ practices showed the values of $\chi^{2}=213.353, \mathrm{df}=73, \mathrm{GFI}=.947, \mathrm{CFI}=.995, \mathrm{RMSEA}=$ .053 , explains goodness of fit of the data.

\subsection{Path Analysis}

There are two extensions of general liner model (GLM), Path analysis and SEM. These methods help the researchers to test a set of regression equations simultaneously. The main feature of SEM is that the observed variable are going to represent small number of latent variables which cannot be measured directly, they can only be inferred by observed measured variables. The path analysis enables us to test the theoretical research model to the full extent including, both direct and indirect effect.

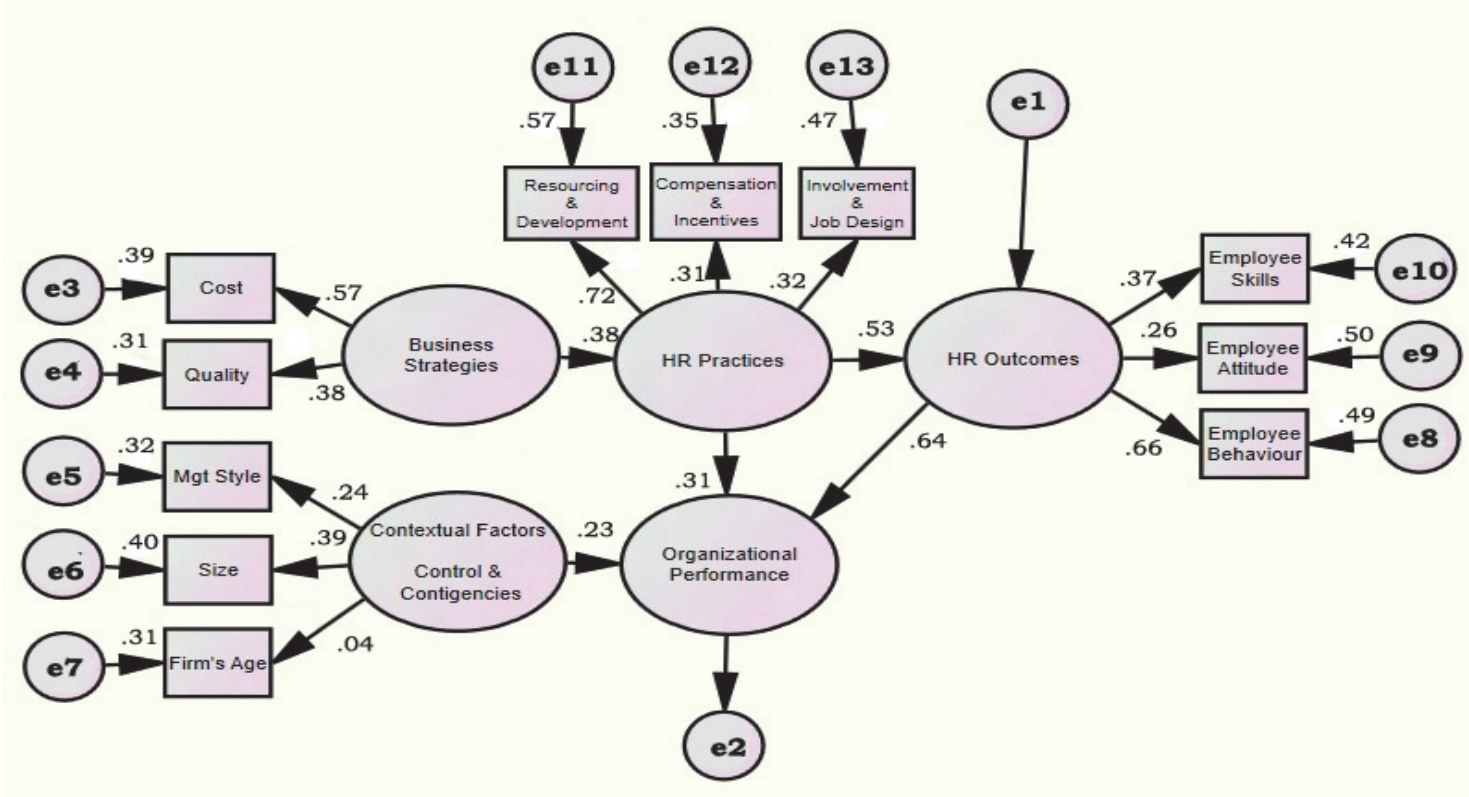

Fig. 2. Path Diagram

\subsection{Structural model}

The structural model values are shown in table 3. By comparing the fit indices values with the recommended values it's found out that model is a good fit. SEM is used in this paper because it is helpful to estimate series of separate but independent, multiple regression equations simultaneously (Hair et al 2006). So SEM using Amos 17 to analyze the selected model is used. The SEM model indices values are as chi-square $/ \mathrm{df}=2.201$ at 59 degree of freedom, $\mathrm{GFI}=.947, \mathrm{RFI}=.961, \mathrm{PNFI}=.907$, $\mathrm{CFI}=.955, \mathrm{RMSEA}=.053$. so we proceed to examine the path coefficients. The model is shown in figure 2. 
Table 3

Structural Model Indices

\begin{tabular}{lcl}
\hline Fit Indices & Benchmark & Value \\
\hline Chi-Square $\chi^{2}$ & & 213.353 \\
df & & 73 \\
$\chi^{2} /$ df $($ CMIN) & $\leq 3$ & 2.921 \\
GFI & $\geq .9$ & .947 \\
PNFI & $\geq .9$ & .907 \\
RFI & $\geq .9$ & .961 \\
CFI & $\geq .9$ & .955 \\
RMSEA & $\leq .1$ & .053 \\
\hline
\end{tabular}

The Table 3 has provided the proof that the Structural model has goodness of fit. So we can start the path analysis. The properties of causal path (standardized path coefficients) showing direct, indirect and total effect of exogenous variable on endogenous variables of the structural equation model in table 4. The effect of exogenous variable directly on endogenous variable is called direct effect. When exogenous variable has effect on endogenous variable through other variables it is called indirect effect. When the direct and indirect effects are added we get total effect. The effect of variables in the structural model is given in table below.

Table 4

Interpretation of effects

\begin{tabular}{llll}
\hline Variables & Direct Effect & Indirect Effect & Total Effect \\
\hline HROutcomes & 0.204 & 0.357 & 0.561 \\
Organizational Performance & 0.329 & 0.273 & 0.602 \\
HR Practices & 0.326 & --- & 0.326 \\
\hline
\end{tabular}

\section{Discussion/ Results}

The indirect effect in path analysis has been defined as equal to the difference between the correlation coefficient and the path coefficient. According to Alwin and Hauser (1975), the direct effect of one variable on another is simply that part of its total effect which is not transmitted via intervening variables. It is the effect which remains when intervening variables have been held constant. Direct effect sometimes also refers to as unmediated effect.

Indirect effects are those parts of a variable's total effect which are transmitted or mediated by variables specified as intervening between the cause and effect of interest in the model. That is, they tell us how much of a given effect occurs because the manipulation of the antecedent variable of interest leads to changes in other variable (Alwin \& Hauser, 1975). A total effect tells us how much change in a consequent variable is induced by a given shift in an antecedent variable, irrespective of the mechanism by which the change may occur (Alwin \& Hauser, 1975).

The HR practices effect on Organizational performance has been found to be positive, but less significant $(\mathrm{r}=0.317, \mathrm{P}=0.001)$ Therefore the first hypothesis (H1: There is positive relationship between HR practices and organizational performance) is also supported. This shows a direct relationship between HR practices and organizational performance, that is an increase in HR practices will increase organizational performance. This result is in line with Rodrigues and Raposo (2011) and Katou and Budhwar (2010). Similarly, the Effect of Human Resource Practices on Human Resource Outcomes has been found to be significant $(\mathrm{r}=0.532, \mathrm{P}=0.001)$ so the second hypothesis $(\mathbf{H 2}$ : HR 
practices positively affect HR outcomes, like employees' cooperation, motivation, and retention) is supported. The Direct and Indirect effects of HR practices on HR outcomes are positive so it showed they have direct relationship. The same result is derived by Katou \& Budhwar (2010) and Kim and Gao (2010).

The effect of HR outcomes on organizational performance has found to be positive and significant $(\mathrm{r}=$ 0.638, $\mathrm{P}=0.001$ ) which proves the third hypothesis (H3: Positive relationship exists between HR outcomes and organizational performance in small firms). HR outcomes and organizational performance showed direct relationship i.e. an increase in HR outcomes, there will be increase in organizational performance. (Katou \& Budhwar, 2010; Klaas et al., 2012).

Business strategies have positive effect but of varying nature were found on HR practices $(\mathrm{r}=0.436$, $\mathrm{P}=0.001$ ), thus supporting Hypothesis $\mathrm{H}_{4}$. This finding is in line with the Luc sels et al., 2006 and Katou, 2008. As far as context factors like contingencies and control are concerned, they have direct positive but weak effect on organizational performance $(\mathrm{r}=0.215, \mathrm{P}=0.001)$. Thus partially supporting $\mathrm{H}_{5}$. As far as the most dominant of all HR practices in small firms are concerned, considering the values of standardized coefficient, selection is the key area of staffing in small firms. This finding found support in Katou and Budhwar (2010), who argue that selection is the most important HRM practice that leads to improved HR outcomes for outstanding organizational performance. The focus during the selection process in the small firms is on the dimension of ability of candidate for a specific job. The managers of these firms see this process as a source of competitive advantage (RBV perspective).

\section{Conclusion}

With respect to the HR outcomes - organizational performance link, we found that all HR outcomes are positively and significantly related with organizational performance. However, it is a bit weak for employee cooperation with management and employees themselves. Although past research has demonstrated that there exists a relationship between HRM practices and organizational performance, it has neglected to investigate the mediating mechanisms, usually called the "black box", through which HRM practices are hypothesized to affect organizational performance. The testing of which HRM practices to be used in a study in new contexts is of much importance (Youndt et al., 2006). Although little is known about the so-called "black box" that lies between the two end points of the HRMperformance relationship i.e. HRM as input and performance as output, this study treats the black box as a mediating stage in the HRM-performance relationship, considering as well that HRM practices are also influenced by contingencies such as business strategies. The operational model in this study advocates that HRM practices directly influence HRM outcomes such as collective skills, attitudes, and behaviors, and thus, indirectly through HRM outcomes improve organizational performance.

Furthermore, it argues that HRM practices are significantly, positively and directly related to organizational performance. In addition, it assumes that HRM practices are influenced by business strategies. Thus, the findings of this study support that the relationship between HRM practices and organizational performance is partially mediated through HRM outcomes and HRM practices are moderated by business strategies. This study has a number of clear implications for both managerscum-owner and decision makers. Notably, the major implications of the study are as follows.

$\checkmark$ Organizational performance depends heavily on HRM outcomes such as skills, attitudes and Behavior. Thus, the emphasis of the development of HRM practices and business strategies should be directed in improving these HRM outcomes.

$\checkmark$ Participation, involvement, compensation, incentives, communication, promotion, training and development, performance appraisal, work design, and selection may constitute in a descending order the important aspects of the HRM strategy. 
$\checkmark$ Satisfaction, motivation, competence, cooperation with management, cooperation among employees, commitment, retention, and presence may constitute in a descending order the important aspects of the HRM outcomes. Although the results indicate that the HR practices affect organizational performance through HR outcomes. Simultaneously we have tried to directly link HR practices with the organizational performance also. However, this analysis did not produced very significant results indicating that the relationship between HR practices and organizational performance is "fully mediated" by HR outcomes. This result support (Jakimow, 2011; Guest, 1997) who assumes that only when all HRM outcomes, as skills, attitudes, and Behavior (as measured by employees' cooperation with management and employees, motivation and commitment and retention and presence respectively) are achieved we can expect higher organizational performance. The indices which are essential for the measurement model are calculated to check the goodness of fit of the model. The convergent and discriminate validates provided the evidences to support the acceptance of measurement. The structural Path model is used to calculate the direct, indirect and total effect of exogenous variable on endogenous variable.

From the discussion till now, it can be established safely that effective HR practices will improve HR outcomes which in turn will improve organizational performance in small firms of this region of the country. We have demonstrated in this study that improving HR practices in small firms can add value to the organizational performance. This conclusion is in line with prior empirical work in small business firms. The "small is beautiful" representations suggest that small firms necessarily lead to close and harmonious working relationships (Bird, 1989) is one of the two extremes about small firms. The importance of small firms as major job supplier, innovators and source of growth is widely recognized. The small firms are supposed to be more homogeneous and informal than large firms. It is generally assumed that small firms are built around entrepreneur or owner manager. Despite this informal nature of these firms, the small firms have different number of employees (managerial and non-managerial) ranging from 20 to 250 to perform day to day operations of the firm. The practices of HRM in small firms are mostly informal. No proper HRM policies were found in most of the small firms but still HR practices dominates the decisions regarding personnel.

All firms have some form of HR practices, even if informal. Most organizations do not have HR professionals in house. Firms with more than 100 employees are likely to develop formal HR practices and departments although HR practices are still in vogue. Early HR choices significantly impact later firm performance. Staffing is very important for small firms and practices employed are often ad hoc. Small firms may lack legitimacy as an employer Fit is an important selection criterion. The focus is on general fit, not specific job requirements. The practices of HRM in small firms are mostly informal. No proper HRM policy was found in most of the small firms but still HR practices dominates the decisions regarding personnel. The findings of this study show that HR Practices in small firms positively affect organizational performance through affecting the mediating outcomes. It means that organizational performance can be significantly enhanced by improving HR outcomes like employee attitude, employee behavior and employee skill.

An improvement in HR outcomes can be achieved by carefully adopting practices like recruitment and selection, training of employees, promotion and compensation. Compensation is different in small firms, as that in large firms, especially as there is more at-risk pay in the mix in small firms. Pay mix changes over the life cycle of the small firm. Small firms have a greater focus on a total rewards perspective than do large firms. Cost of training and time away from work for it are essential considerations. In small firms, unstructured training, informal job instruction, and socialization are a big part of the training process. In small firms, the result shows that employee promotion has significant effect on organizational performance as compared to other HR practices. Though the theoretical model explaining the relationship between the HR practices and organizational performance is a bit advanced as far as small firms are concerned, however, in this study we have attempted to test it empirically. 
During the last decade of twentieth century, the research on small firms is mostly confined to the financial performance of the firms. The three major areas of HR practices in small firms are staffing, training and motivation. These practices positively shape the outcomes of these practices. Which of these practices play the most significant role in designing the performance into reality in small firms is yet to explore. The results of the study shows that in small manufacturing firms, HR practices like recruitment, selection, training and compensation affect organizational performance. Nevertheless, it is also concluded these practices do not have a direct impact on organizational performance, but their impact is reasonably mediated by HR outcomes like employee skills, employee attitudes and employee behaviors.

\subsection{Recommendations}

This study has a number of clear implications for both managers-cum-owner and decision makers. Notably, the major implications of the study are as follows.

\subsection{Recommendation for Managers-cum-Owners}

Small firms should be more focused on providing their employees market competitive compensation along with other incentives. Small firms should adopt HR policies about their personnel practices in order to maintain credibility and justification of their practices regarding HR. Organizational performance depends heavily on HRM outcomes such as employee skills, attitudes and behavior. Thus, the emphasis of the development of HRM practices should be directed in improving these HRM outcomes. Owner-manager should be made aware of the importance of maintaining a balance in HR practices that enable proper accountability and control and reduce the risk of litigation. Whilst at the same time, these practices provide the small firms an adequate flexibility for response to changing requirement and operations. Participation, compensation, incentives, promotion, training and performance appraisal, recruitment and selection may constitute in a descending order the important aspects of the HRM strategy. Satisfaction, motivation, competence, cooperation with management, cooperation among employees, commitment, retention, and presence may constitute in a descending order the important aspects of the HRM outcomes.

\subsection{Recommendation for decision makers}

Keeping in mind the importance of small firms for an economy of underdeveloped country like Pakistan, the survival of these firms is an issue of continuous concern. It may be more effective to stimulate more formal HRM practices by providing technology transfer assistance, than by mandating that specific practices are adhered to. In the absence of sanctions or additional resources, official mandates that communicate stakeholder expectations, appear to have very small impact on adoption of appropriate HRM practices. Simply increasing the information about implementation in such documents (e.g. by providing examples of written job descriptions) may improve the adoption rate. Other efforts to lower search and development costs (as part of the total transaction costs) may also have a positive impact on HRM implementation. There is a general awareness that historically, government agencies and government-sponsored small business assistance programs can play an effective role in technology transfer to small companies. Our conclusions presume that more formal HRM practices are beneficial, and that we have a clear understanding of what they entail. However, shortcomings in definition and measurement in past research suggest the need for further validation of HRM practices in small firms, and a more careful definition of what is meant by formalization of HRM practices. Hopefully future research will begin to address these issues more systematically.

\subsection{Limitations of the study}

All research has its limitations and ours is no different. The findings of this study can be interpreted within the context of their limitations. The study did not examine industry effects on the changes in HRM practices and this could be the subject of future research. A longitudinal examination of HRM 
practices of firms as they progress through various growth stages should complement the findings in this research. This study is based on the data collected from small manufacturing units in Hazara division and we are thus unable to pronounce upon the extent to which these results can be generalized to small companies in other parts of the country. Furthermore, and due to the difficulty of collecting data from employees at lower managerial levels in small firms, we did not consult the voices of employees who actually experience the HRM practices and are so intimately involved in translating practices into performance. Similarly, future research should not only consult the crafters of policies but it should also consider the voices of employees.

\section{Acknowledgement}

The authors would like to thank the anonymous referees for constructive comments on earlier version of this paper.

\section{References}

Alwin, D. F., \& Hauser, R. M. (1975). The decomposition of effects in path analysis. American Sociological Review, 37-47.

Audretsch, D. B., \&Thurik, A. R. (2004). A model of the entrepreneurial economy (No. 1204). Papers on entrepreneurship, growth and public policy.

Baron, J. N., \& Kreps, D. M. (1999). Strategic human resources: Frameworks for general managers. New York: Wiley.

Barrett, R., Mayson, S., \&Warriner, N. (2006, July). Growth oriented small firms in Australia: How do they do what they do with human resource management. In Proceedings of the 2 nd Annual ACREW Conference, Prato, Italy (pp. 1-3).

Bird, B. J. (1989). Entrepreneurial behavior.37 Taylor \& Francis

Chenhall, R. H., \& Lang field Smith, K. (2007). Multiple perspectives of performance measures. European Management Journal, 25(4), 266-282.

Cronbach, L. J. (1951). Coefficient alpha and the internal structure of tests.Psychometrika, 16(3), $297-$ 334.

Cunningham, L. X. (2010). Managing human resources in SMEs in a transition economy: evidence from China. The International Journal of Human Resource Management, 21(12), 2120-2141.

Deshpande, S. P., \&Golhar, D. Y. (1994). HRM practices in large and small manufacturing firms: A comparative study. Journal of Small Business Management, 32(2), 49.

Evans, J. R. (2004). An exploratory study of performance measurement systems and relationships with performance results. Journal of Operations Management, 22(3), 219-232.

Fornell, C., \& Larcker, D. F. (1981). Evaluating structural equation models with unobservable variables and measurement error. Journal of Marketing Research, 39-50.

Golhar, D. Y., \& Deshpande, S. P. (1997). HRM practices of large and small Canadian manufacturing firms. Journal of Small Business Management, 35(3), 30.

Guest, D. E. (1997). Human resource management and performance: a review and research agenda. International Journal of Human Resource Management, 8(3), 263-276.

Griffin, R. W. (1991). Research notes. Effects of work redesign on employee perceptions, attitudes, and behaviors: A long-term investigation. Academy of management Journal, 34(2), 425-435.

Hair, J. F., Anderson, R. E., Tatham, R. L., \& William, C. (1998). Black (1998), Multivariate data analysis.

Heneman, R. L., Tansky, J. W., \& Camp, S. M. (2000). Human resource management practices in small and medium-sized enterprises: Unanswered questions and future research perspectives. Entrepreneurship Theory and Practice, 25(1), 11-26. 
Hornsby, J. S., \&Kuratko, D. F. (2003). Human resource management in US small businesses: A replication and extension. Journal of Developmental Entrepreneurship, 8(1), 73.

Hill, R., \& Stewart, J. (2000). Human resource development in small organizations. Journal of European Industrial Training, 24(2/3/4), 105-117.

Hyvönen, J. (2007). Strategy, performance measurement techniques and information technology of the firm and their links to organizational performance.Management Accounting Research, 18(3), 343366.

Ittner, C. D., \&Larcker, D. F. (1997). Quality strategy, strategic control systems, and organizational performance. Accounting, Organizations and Society, 22(3), 293-314.

Jakimow, T. (2011). Family involvement in small, local nongovernmental organizations. Nonprofit Management and Leadership, 22(1), 21-35.

Kim, Y., \&Gao, F. Y. (2010). An empirical study of human resource management practices in family firms in China. The International Journal of Human Resource Management, 21(12), 2095-2119.

Klaas, B. S., Semadeni, M., Klimchak, M., \& Ward, A. K. (2012). High-performance work system implementation in small and medium enterprises: A knowledge-creation perspective. Human Resource Management, 51(4), 487-510.

Katou, A. A., \& Budhwar, P. S. (2010). Testing competing HRM-performance linkage models: evidence from the Greek manufacturing sector. European Journal of International Management, 4(5), 464-487.

Langfield-Smith, K. (1997). Management control systems and strategy: a critical review. Accounting, Organizations and Society, 22(2), 207-232.

MacDuffie, J. P. (1995). Human resource bundles and manufacturing performance: Organizational logic and flexible production systems in the world auto industry. Industrial \& Labor Relations Review, 48(2), 197-221.

McEvoy, G. M. (1984). Small business personnel practices. Journal of Small Business Management (pre-1986), 22(000004), 1.

Marchington, M., Carroll, M., \& Boxall, P. (2003). Labour scarcity and the survival of small firms: a resource-based view of the road haulage industry.Human Resource Management Journal, 13(4), 522.

Mayson, S., \& Barrett, R. (2006). Human resource management in small firms: evidence from growing small firms in Australia.

Michael, B., \& Chris.(1990).Human resource management and the emergent strategy of small to medium-sized business units. The International Journal of Human Resource Management, 1(3), 233-250.

Pfeffer, J. (1995). Competitive advantage through people: Unleashing the power of the work force. Harvard Business Press.

Prahalad, C. K., \& Hamel, G. (2001). The core competence of the corporation. Harvard Business Review.

Raykov, T. (2001). Bias of Coefficient afor Fixed Congeneric Measures with Correlated Errors. Applied Psychological Measurement, 25(1), 69-76.

Rodrigues, R. G., \&Raposo, M. (2011). Entrepreneurial orientation, human resources information management, and firm performance in SMEs. Canadian Journal of Administrative Sciences/Revue Canadienne des Sciences de l'Administration, 28(2), 143-153.

Sels, L., De Winne, S., Maes, J., Delmotte, J., Faems, D., \&Forrier, A. (2006). Unravelling the HRMPerformance link: Value-creating and cost-increasing effects of small business HRM. Journal of Management Studies, 43(2), 319-342.

Snell, S. A., \&Youndt, M. A. (1995). Human resource management and firm performance: Testing a contingency model of executive controls. Journal of Management, 21(4), 711-737.

Tangen, S. (2003). An overview of frequently used performance measures.Work Study, 52(7), 347-354.

Ukko, J. K. (2009). Managing through measurement: A framework for successful operative level performance measurement. Lappeenranta University of Technology. 
Youndt, M. A., Snell, S. A., Dean, J. W., \&Lepak, D. P. (1996). Human resource management, manufacturing strategy, and firm performance Academy of Management Journal, 39(4), 836-866.

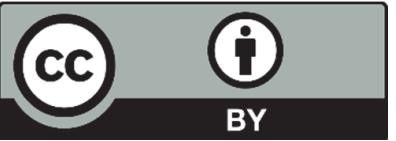

(C) 2016 by the authors; licensee Growing Science, Canada. This is an open access article distributed under the terms and conditions of the Creative Commons Attribution (CC-BY) license (http://creativecommons.org/licenses/by/4.0/). 